\title{
Local radiotherapy increases the level of autoantibodies to ribosomal P0 protein but not to heat shock proteins, extracellular matrix molecules and EGFR/ErbB2 receptors in prostate cancer patients
}

\author{
GIANLUCA INGROSSO ${ }^{1}$, MASSIMO FANTINI $^{2}$, ALESSANDRA NARDI $^{3}$, MONICA BENVENUTO $^{2}$, \\ PAMELA SACCHETTI ${ }^{4}$, LAURA MASUELLI ${ }^{4}$, ELISABETTA PONTI ${ }^{1}$, GIOVANNI VANNI FRAJESE ${ }^{5}$, \\ FLORIGIO LISTA $^{6}$, ORAZIO SCHILLACI ${ }^{1}$, RICCARDO SANTONI ${ }^{1}$, ANDREA MODESTI $^{2}$ and ROBERTO BEI ${ }^{2}$ \\ Departments of ${ }^{1}$ Diagnostic Imaging, Molecular Imaging, Interventional Radiology and Radiotherapy, \\ ${ }^{2}$ Clinical Sciences and Translational Medicine and ${ }^{3}$ Mathematics, University of Rome 'Tor Vergata', Rome; \\ ${ }^{4}$ Department of Experimental Medicine, University of Rome 'Sapienza', Rome; ${ }^{5}$ Faculty of Motor and Adaptive Sciences, \\ University of Cassino, Cassino; ${ }^{6}$ Laboratory of Molecular Biology, Army Medical Research Centre, Rome, Italy
}

Received October 1, 2012; Accepted October 22, 2012

DOI: $10.3892 /$ or.2012.2197

\begin{abstract}
Prostate cancer is a common cancer among men in developed countries. Although hormonotherapy and radiotherapy (RT) represent valid therapies for prostate cancer treatment, novel immunological approaches have been explored. The development of clinical trials employing cancer vaccines has indicated that immune response to tumor antigens can be boosted and that vaccine administration can improve patient survival. Immune response to tumor antigens could also be enhanced after standard therapies. In the present study, we determined the occurrence of antibodies to extracellular matrix (ECM) molecules, heat shock protein (HSP), ribosomal P0 protein, EGFR, ErbB2 and prostate-specific antigen (PSA) in 35 prostate cancer patients prior to and following local RT and hormonotherapy. We demonstrated that immunity to P0, ECM molecules [collagens (C) CI, CIII, CV, fibronectin (FN) and laminin (LM)] and to HSP90 was associated with malignancy in untreated patients. None of the patient sera showed antibodies to EGFR, while 2 and 1 patients showed reactivity to ErbB2 and PSA, respectively. We also demonstrated that 8 months after therapy the IgG serum levels to CI, CIII, FN and HSP90 significantly decreased. Conversely, the level of P0 autoantibodies increased after therapy in 10 patients. Five of the 10 patients with increased levels of P0 autoantibodies
\end{abstract}

Correspondence to: Professor Roberto Bei, Department of Clinical Sciences and Translational Medicine, University of Rome 'Tor Vergata', Via Montpellier 1, I-00133 Rome, Italy

E-mail: bei@med.uniroma2.it

Key words: $\mathrm{P} 0$, immune response, prostate cancer, radiotherapy, heat shock protein, extracellular matrix were treated with RT plus hormonotherapy. Treatment of patients did not change the levels of antibodies against EGFR, ErbB2 and PSA. Our results indicated that the modification of antibody level to self molecules after standard treatment of prostate cancer patients is influenced by the type of antigen. Ribosomal P0 protein appears to be a high immunogenic antigen and its immunogenicity increases following RT. In addition, 10 patients with increased levels of autoantibodies to P0 showed PSA mean levels lower than the remaining 25 patients at 18 months. This study may contribute to a better understanding of the immunobiological behavior of prostate cancer patients following standard treatment.

\section{Introduction}

Prostate cancer, whose incidence and mortality varies broadly, is a common cancer among men in developed countries (1). Although hormonotherapy and radiotherapy (RT) represent valid approaches for prostate cancer treatment, there is a need for novel therapies that are based on mechanisms which do not overlap with standard therapies and that can improve patient survival $(2,3)$. Indeed, novel immunological approaches have been explored for prostate cancer treatment, relying on the fact that a significant number of prostate cancer patients have antibodies against different tumor antigens [prostate-specific antigen (PSA), ErbB2, prostatic acid phosphatase (PAP), prostasome-derived proteins] and other structural cellular antigens (ribosomal proteins, cytoskeleton and nuclear associated proteins) and that the presence of a significant tumor lymphocyte infiltrate is associated with a better prognosis in prostate cancer patients (4-11). The development of clinical trials employing cancer vaccines targeting PSA, PAP and prostate membrane antigen has clearly indicated that immune response to tumor antigens can be boosted and, in some cases, that vaccine administration can improve patient survival (12-15). On the other hand, it has been observed that immune response 
to tumor antigens can also be enhanced after standard therapies in prostate cancer patients (16). Significant evidence indicates that RT exerts its effect not only by the elimination of the RT vulnerable cancer cells but also by modification of the tumor microenvironment inducing oxidative stress and inflammation (16-20). Although the evidence that radiation injury perturbs innate and adaptive immunity, immune response to radiation tissue damage is not predictable and remains incompletely understood. However, it has been reported that ionizing radiations induce upregulation of heat shock proteins (HSPs) and growth factor receptors in fibroblasts and extracellular matrix (ECM) remodeling in fibroblasts and mammary gland (21-24). In addition, it has been observed that RT induces reoxygenation of hypoxic tumors and this phenomenon triggers the production of reactive oxygen species (ROS) which alter molecule structure (25-27). Reoxygenation of HeLa cancer cells after hypoxia was shown to increase expression of several proteins including the ribosomal P0 protein (26).

ECM is a composite and dynamic macromolecular network with both structural and regulatory functions. ECM components belong to four major types of macromolecules: the collagens, elastin, proteoglycans and non-collagenous glycoproteins (laminin, fibronectin, tenascin). A high incidence of autoantibodies to ECM components during inflammation and cancer has been reported (28-35). HSPs are overexpressed in several tumors and are implicated in cancer cell proliferation, metastasis and immune response (36). Overexpression of HSPs or autoantibodies to HSPs were associated with either a poor or good prognosis in cancer patients $(36,37)$. The ribosomal $\mathrm{P}$ proteins (P0, $38 \mathrm{kDa}$; $\mathrm{P} 1,19 \mathrm{kDa}$; and $\mathrm{P} 2,17 \mathrm{kDa})$ constitute a pentameric complex forming the ribosomal stalk of the $60 \mathrm{~S}$ ribosomal subunit in the eukaryotic cells (38). P0 exists as a free protein in the cytoplasm and on the surface of cancer cells (39). The presence of autoantibodies to ribosomal $\mathrm{P}$ proteins in sera of patients with systemic lupus erythematosus (LES) has been demonstrated $(40,41)$. We recently demonstrated the presence of autoantibodies to ribosomal $\mathrm{P}$ proteins in head and neck as well as breast cancer patients $(42,43)$. Autoantibodies to P0 protein have shown to mediate cell apoptosis (44).

In this study, we determined the occurrence of antibodies to ECM components, HSPs, ribosomal P0 protein, EGFR, ErbB2 and PSA in prostate cancer patients before and after local RT and hormonotherapy. This study provides insight into the immunobiological behavior of prostate cancer patients following standard treatment.

\section{Materials and methods}

Study population. The study protocol was approved by the Ethics Committee of the University of Rome 'Tor Vergata'. Each patient was given a detailed description of the procedure and was required to sign an informed consent prior to participation in this study. Thirty-five consecutive patients with localized prostate cancer underwent CT-planned radical 3D conformal RT at the Radiation Oncology Therapy Unit of the University of Rome 'Tor Vergata'. The median age at the time of treatment was 72 years (range 46-78 years); 21 patients were classified as T1c clinical stage, 8 as T2a, 3 as T2c, 2 as T1a and 1 patient was T3b (TNM, American Joint Committee on Cancer 2002). The Gleason score was $6(3+3)$ in 20 patients, $7(3+4)$ in 5 cases and $7(4+3)$ in 3 cases, $8(4+4)$ in 3 cases and 4 patients had a Gleason score of, respectively, $5(3+2), 8(5+3), 9(4+5)$ and $10(5+5)$; 9/35 cases were treated with hormone-releasing hormone agonist in association with RT. The median PSA value before RT was $7.9 \mathrm{ng} / \mathrm{ml}$ (range $0.53-72.3 \mathrm{ng} / \mathrm{ml}$ ).

The serum of patients was collected prior to and 8 months following the last RT treatment. Sera from blood donors $(n=29)$ collected from the University of Rome 'Sapienza' transfusion center were used as control. Patient and control sera were stored at $-20^{\circ} \mathrm{C}$ until use.

Radiation therapy. Bowel preparation was obtained suggesting a diet in combination with a daily mild laxative to reduce intestinal gas and obtain a reproducible bowel volume during CT and MRI acquisition and treatment sessions. For bladder preparation, patients were asked to empty their bladder for better daily prostate localization.

CT scanning was performed with a GE LightSpeed ${ }^{\circledR}$ Scanner (GE Healthcare Diagnostic Imaging, Slough, UK). The scan was to start at the level of the iliac crests and continue down through the perineum, with a $2.5-\mathrm{mm}$ slice. CT images were transferred to Precise Plan treatment planning system (Elekta Oncology Systems, Crawley, UK).

For each patient, the clinical target volume (CTV) and organs at risk (OARs) were outlined by the same radiation oncologist. The target volume irradiated to $66 \mathrm{~Gy}\left(\mathrm{CTV}_{1}\right)$ consisted of prostate and seminal vesicles; the boost irradiated to $76 \mathrm{~Gy}\left(\mathrm{CTV}_{2}\right)$ was the prostate only. Planning target volumes $\left(\mathrm{PTV}_{1}\right.$ and $\left.\mathrm{PTV}_{2}\right)$ were generated by an asymmetric expansion of CTVs (6 mm in all directions except at the posterior margin, where a 5-mm expansion was used). The rectum was contoured on as solid organ from the 8 th slice $(2 \mathrm{~cm})$ above the anal verge to the rectosigmoid junction; the bladder was contoured in its entirety; the penile bulb was defined as a pear-shaped structure comprising the proximal part of the corpus spongiosum; the femurs were defined too. Three-dimension conformal RT treatment planning, with a six-field arrangement, was obtained. For an adequate PTV coverage, it was accepted that the $95 \%$ of PTV volume was covered by $95 \%$ of the prescribed dose and that the maximum dose did not exceed $107 \%$ of the prescribed dose. Daily fractions of 2 Gy (5 days a week) were delivered with conformal shaped treatment fields (15 MV) using the multi-leaf collimator (MLC; $1 \mathrm{~cm}$ leaf width) of an Elekta Precise linear accelerator (Elekta Precise Treatment System Plus $^{\mathrm{TM}}$ ). Two orthogonal portal images were used in order to check set-up alignment. Digitally reconstructed radiographs (DRRs), obtained from the CT localization scans, were used as reference images. A matching software was applied to quantify set-up errors between DRRs and portal images.

For biochemical failure definition we referred to the Phoenix definition, revised by ASTRO and RTOG in Phoenix, as a rise in PSA by $2 \mathrm{ng} / \mathrm{ml}$ or more above the nadir PSA (defined as the lowest PSA achieved).

Acute rectal toxicity (within 90 days from the start of RT) and late rectal toxicity were scored by the radiation oncologist, according to the RTOG/EORTC toxicity scale.

Purified ECM molecules, HSPs, ribosomal PO protein, PSA, LTR-EGFR and LTR-ErbB2 transfectants and antibodies. Purified human type I, III, IV and V collagens (CI, CIII, 
CIV and CV), fibronectin (FN) and PSA were obtained from Chemicon International (Temecula, CA, USA). Purified laminin (LM) was obtained from Sigma-Aldrich (St. Louis, MO, USA). Purified HSPs included HSP27 and HSP90 $\alpha$ (human recombinant, StressMarq ${ }^{\mathrm{TM}}$ Biosciences Inc., Victoria, BC, Canada) and HSP65 (M. Tuberculosis recombinant, LIONEX Diagnostics and Therapeutics GmbH, Germany). The purity of antigens was $>95 \%$ by SDS-PAGE and Coomassie Blue staining. Mouse monoclonal antibodies anti-human CI, CIII, CIV and CV were obtained from Chemicon International. Mouse monoclonal anti-human FN and rabbit polyclonal antihuman LM, as well as peroxidase-conjugated antibodies anti-human $\operatorname{IgG}$ and $\operatorname{IgM}$ or anti-mouse and anti-rabbit $\operatorname{IgG}$, were obtained from Sigma-Aldrich. Antibodies to HSPs were purchased from StressMarq ${ }^{\mathrm{TM}}$ Biosciences Inc. or Santa Cruz Biotech., Inc. (Santa Cruz, CA, USA). Anti-PSA antibody was purchased from Dako (Carpinteria, CA, USA). LTR-EGFR and LTR-ErbB2 transfectants and anti-EGFR and anti-ErbB2 antibodies were previously described (45-47). Ribosomal $\mathrm{P} 0$ protein generation was previously described $(42,43)$.

Enzyme-linked immunosorbent assay (ELISA). Sera were assayed for the presence of antibodies directed toward native ECM and HSP antigens by ELISA as previously described $(33,34,48)$. Briefly, ECM and HSP antigens, as well as bovine serum albumin (BSA), were diluted at $1-2 \mu \mathrm{g} / \mathrm{ml}$. One hundred microliters of each mixture were incubated overnight at $37^{\circ} \mathrm{C}$ in polyvinyl chloride microtiter plates (Dynatech, Chantilly, VA, USA). Antigen-coated wells were then blocked with $5 \%$ non-fat dry milk in PBS for $1 \mathrm{~h}$ at $37^{\circ} \mathrm{C}$ and incubated with human sera. Sera were initially assayed at 1:25, 1:50 and 1:100 dilutions. The 1:100 dilution was chosen for further experiments since it was the highest serum concentration that lacked background reactivity. Each serum was assayed in duplicate for reactivity to ECM and HSP antigens or BSA. Anti-ECM and anti-HSP antibodies diluted at $1 \mu \mathrm{g} / \mathrm{ml}$ were used as positive controls. After an overnight incubation at $4^{\circ} \mathrm{C}$, the plates were washed 5 times with $1 \%$ non-fat dry milk in PBS and goat anti-human IgG or goat anti-mouse or anti-rabbit IgG peroxidase-conjugated antibodies were added and incubated for $1 \mathrm{~h}$ at $37^{\circ} \mathrm{C}$. The plates were washed and the wells were layered with a solution containing o-phenylenediamine dihydrochloride in the presence of $\mathrm{H}_{2} \mathrm{O}_{2}$. The reaction was blocked with $50 \mu \mathrm{l}$ of $\mathrm{H}_{2} \mathrm{SO}_{4}(4 \mathrm{~N})$ and the absorbance of the samples was read at $492 \mathrm{~nm}(33,34)$.

Western blotting. Electrophoresis of purified recombinant P0 protein or PSA (0.2-0.5 $\mu \mathrm{g} /$ lane) or NIH3T3 and NIH-LTREGFR and LTR-ErbB2 cells (100 $\mu \mathrm{g} /$ lane) was carried out in denaturing 10-12\% SDS polyacrylamide gels. Following electrophoresis, the proteins were transferred to nitrocellulose membranes at $40 \mathrm{~V}$ for $1 \mathrm{~h}$ (49-51). The membranes were blocked for $6 \mathrm{~h}$ in a washing solution $(0.1 \%$ Tween-20 in Trisbuffered saline, $\mathrm{pH} 7.6$ ) containing $5 \%$ non-fat dry milk and subsequently incubated overnight at $4^{\circ} \mathrm{C}$ with either human sera or specific monoclonal and polyclonal antibodies. Human sera were initially titrated at 1:25, 1:50 and 1:100 dilutions. The 1:100 dilution was chosen for further experiments since it was the highest serum concentration lacking background reactivity. After extensive washings, the membranes were incubated with goat anti-human IgG or goat anti-mouse or anti-rabbit IgG peroxidase-conjugated antibodies. The immunocomplexes were finally visualized by means of the Supersignal West Pico chemiluminescence kit (Pierce, Rockford, IL, USA) (52). Criteria of serum positivity toward a given antigen consisted in the appearance of an immunoreactive band co-migrating with that detected by the positive control antibody $(45,53)$.

The intensity of coloring of immunoreactive P0 band was expressed as densitometric unit(s) (DU) and was obtained using the NIH Pro-Image 1.5 software after blot scanning by a UMAX VISTA SUPER SPEEDY scanner (53). Values obtained were used for statistical analysis to determine the significance of antibody variances to P0 before and after therapy.

Statistical analysis. Since several distributions were skew departing from normality and sample size was limited a nonparametric approach was preferred in the analysis. Continuous variables were described by median, first and third quartiles and range, categorical variables as frequencies. In order to show the distributions of humoral immune responses, Box and Whisker plots were created. The bottom and top edges of the box are located at the 25th and 75th percentiles of the sample and, within the box, the median is displayed as a line and the mean as a diamond. Outliers are observations that are more extreme than the upper and lower fences located at $\pm 1.5 \mathrm{x}$ interquartile range. Horizontal lines identify the largest and the smallest value within these fences.

Wilcoxon sum rank test and Wilcoxon signed-rank test were utilized as location tests in case of independent samples and paired observations, respectively. A non-parametric analysis of variance was used for assessing the effect of clinical pathological variables and type of therapy on humoral immune responses. For this purpose two classes were defined for both Gleason score ( $\leq 6$ vs. $>6)$ and PSA before therapy ( $\leq 10$ vs. $>10)$.

The association between categorical variables was assessed by the $\chi^{2}$ test; Fisher's exact test was preferred in case of sparse tables. Difference in proportions for paired observations was evaluated by the McNemar test.

\section{Results}

Humoral immune response to ECM molecules before and after therapy. Sera from 35 patients with prostate cancer and 29 healthy donors were analyzed for the presence of autoantibodies to purified ECM proteins including different types of collagen (CI, CIII, CIV and V) and glycoproteins such as $\mathrm{LM}$ and FN. In order to reveal the reactivity of patient immunoglobulin $\mathrm{G}$ to conformational epitopes of the ECM, serum samples were analyzed by ELISA. The level of IgG of both healthy donors and prostate cancer patients to different ECM molecules is represented in Fig. 1.

Significant differences between healthy donors and untreated patients were detected for the IgG serum levels to $\mathrm{CI}$ (median value 0.43 vs. $0.55, \mathrm{p}=0.0046), \mathrm{CIII}(0.35$ vs. $0.47, \mathrm{p}=0.0006)$, CV (0.28 vs. $0.38, \mathrm{p}=0.0028), \mathrm{FN}(0.09$ vs. $0.22, \mathrm{p}<0.0001)$ and LM (0.20 vs. $0.33, \mathrm{p}=0.0004)$. The level of autoantibodies to CIV in untreated patients was not significant compared to that of healthy donors. The increased autoantibody level to CI, CIII, CV, FN and LM in prostate cancer patients was not associated with PSA level and Gleason score. 

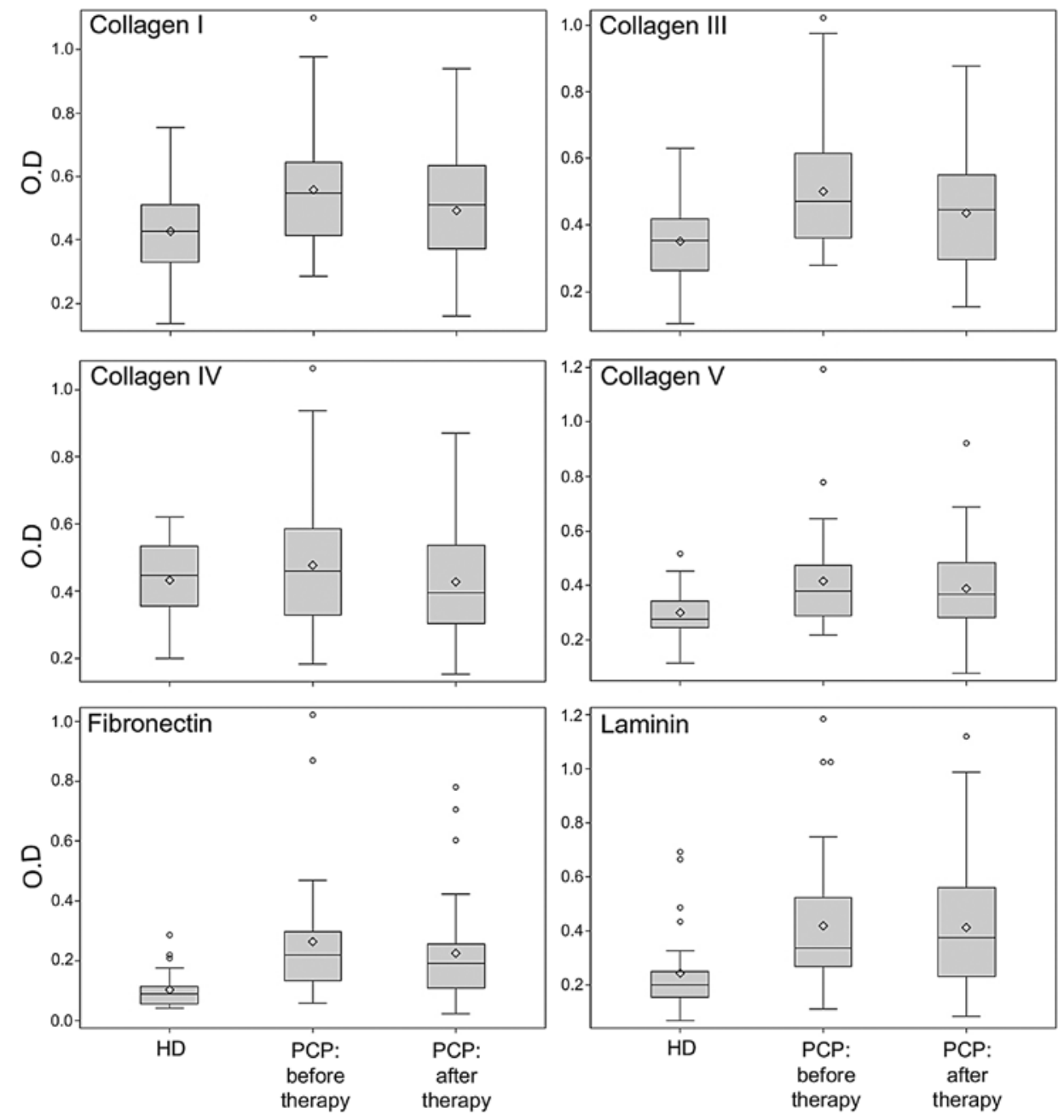

Figure 1. Levels of autoantibodies to ECM molecules in prostate cancer patients. The level of autoantibodies was measured in serum of healthy donors (HD, $\mathrm{n}=29$ ) and prostate cancer patients (PCP, $\mathrm{n}=35$ ) before and after therapy by ELISA and expressed as optical density (OD) at $492 \mathrm{~nm}$. The bottom and top edges of the box are located at the 25th and 75th percentiles of the sample and, within the box, the median is displayed as a line and the mean as a diamond. Outliers are observations that are more extreme than the upper and lower fences located at $\pm 1.5 \mathrm{x}$ interquartile range. Horizontal lines identify the largest and the smallest value within these fences.

It is important to note that 8 months after therapy the $\mathrm{IgG}$ serum levels to $\mathrm{CI}$ (median value 0.55 vs. $0.51, \mathrm{p}=0.0009$ ), $\mathrm{CIII}$ (median value 0.47 vs. $0.44, \mathrm{p}=0.0003$ ) and $\mathrm{FN}$ (median value 0.22 vs. $0.19, p=0.0003$ ) significantly decreased. Conversely, after treatment, no significant difference was observed in the level of IgG to CIV, CV and LM. The decrease of autoantibody level to ECM molecules was not associated with clinical pathological variables or type of therapy.

Humoral immune response to HSPs before and after therapy. The $\mathrm{IgG}$ level of both healthy donors and prostate cancer patients to HSPs is shown in Fig. 2. The patient serum IgG level to HSP90 was significantly higher than that of healthy donors (0.51 vs. $0.58, p=0.0406$ ). Conversely, the levels of HSP27 and HSP65 IgG, although higher in patients with prostate cancer, were not significant compared to those of healthy donors. The increased level of autoantibodies to HSP90 was not associated with clinical pathological variables. However, after therapy, the IgG levels to HSP27 (median value 0.16 vs. 0.14 , $\mathrm{p}=0.0205$ ), HSP65 (median value 0.31 vs. $0.27, \mathrm{p}=0.0098$ ) and HSP90 (median value 0.58 vs. $0.54, \mathrm{p}=0.0012$ ) significantly decreased. For the IgG levels to HSP27, this decrease was associated with levels of PSA before therapy: for patients with PSA $\leq 10$ the median decrease was 0.045 while for patients with PSA $>10$ a slight median increase of 0.005 was observed $(\mathrm{p}=0.0394)$. For the IgG levels to HSP90, this decrease was associated with levels of Gleason before RT: for patients with Gleason $\leq 6$ the median decrease was 0.075 while for patients with Gleason $>6$ a slight median increase of 0.015 was observed $(\mathrm{p}=0.0483$ ). No significant effect of hormonotherapy was detected.

Humoral immune response to ribosomal P0 protein, EGFR/ ErbB2 and PSA before and after therapy. Employing the GST-P0 ribosomal protein, NIH3T3-EGFR or -ErbB2 transfectant cell lines or a commercial source of human PSA, serum from patients and normal donors was subjected to qualitative immunoblot analysis. The GST protein, NIH3T3 cells and BSA were used as control of specific immunoreactivity of serum with GST-P0, LTR-transfectant cell lines and PSA, respectively. Criteria of serum positivity toward a given antigen consisted in the appearance of a specific immunoreactive band in the antigen source sample, co-migrating with those detected by the positive control antibody. Representative experiments are illustrated in Fig. 3. 

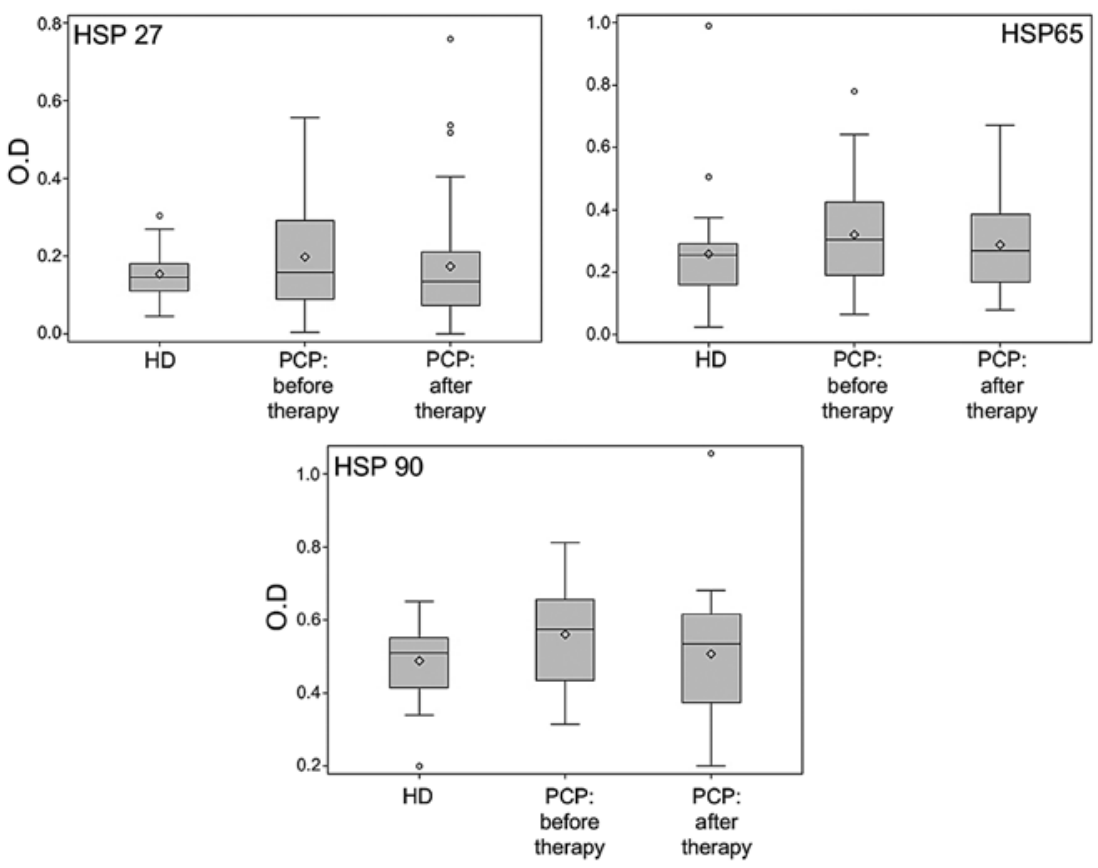

Figure 2. Levels of autoantibodies to HSPs in prostate cancer patients. The level of autoantibodies was measured in serum of healthy donors (HD, $\mathrm{n}=29)$ and prostate cancer patients (PCP, $\mathrm{n}=35$ ) before and after therapy by ELISA and expressed as optical density (OD) at $492 \mathrm{~nm}$. The bottom and top edges of the box are located at the 25th and 75th percentiles of the sample and, within the box, the median is displayed as a line and the mean as a diamond. Outliers are observations that are more extreme than the upper and lower fences located at $\pm 1.5 \mathrm{x}$ interquartile range. Horizontal lines identify the largest and the smallest value within these fences.

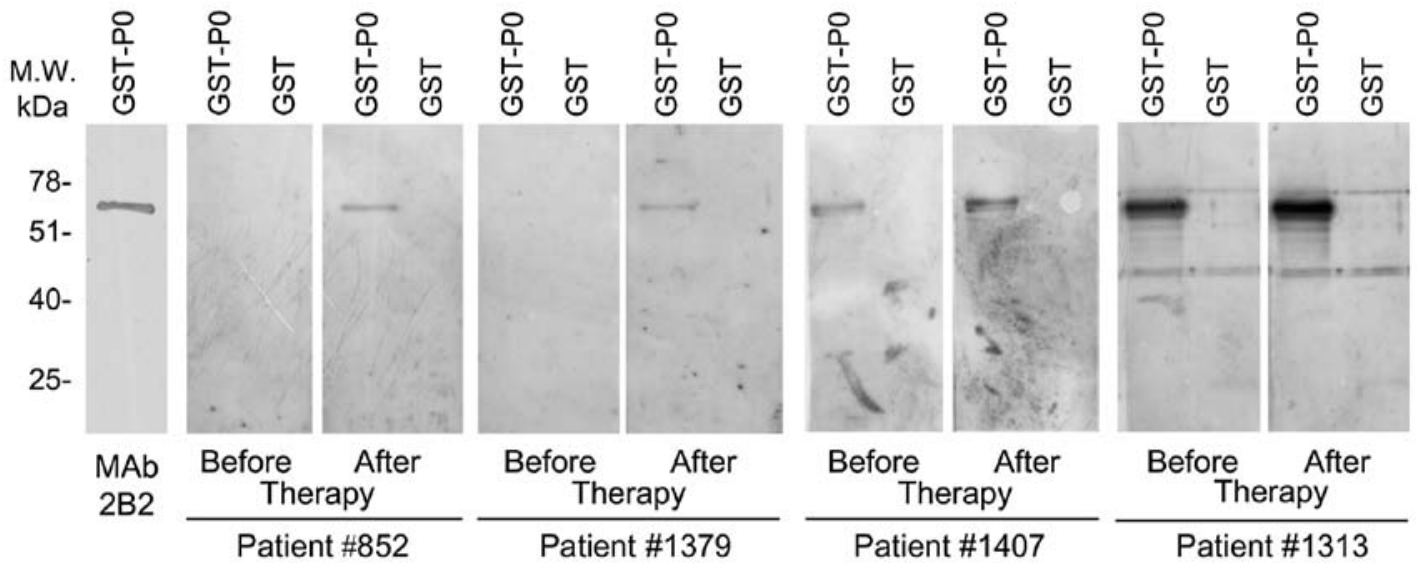

Figure 3. Detection of anti-P0 autoantibodies in prostate cancer patients. Immunoblot analysis of GST-P0 protein and GST employing serum from prostate cancer patients, nos. 852, 1379, 1407 and 1313.

None of the healthy donor sera showed reactivity to P0 protein, EGFR, ErbB2 or PSA. Conversely, 6 out of the 35 prostate cancer patient sera reacted to $\mathrm{P} 0$ protein. Immunity to P0 protein was associated with malignancy $(\mathrm{p}=0.0279)$. No patient serum showed antibodies to EGFR, while 2 and 1 patients showed reactivity to ErbB2 and PSA, respectively.

Of note, 8 months after therapy the number of patients displaying antibodies to $\mathrm{P} 0$ increased (6/35 before therapy vs. $11 / 35$ after therapy). We quantitatively evaluated the reactivity of the serum to the P0 protein by measuring the intensity of the immunoreactive P0 band. Our results indicated that reactivity to $\mathrm{P} 0$ also increased in 5 of the 6 patients with pre-existing autoantibodies to P0 before therapy (median level 3.22 vs. 6.41). Overall, the level of autoantibodies to P0 increased after therapy in 10 patients (median level before 0.87 and after therapy $3.02, p=0.0020$ ). It is noteworthy that $50 \%$ of the 10 patients with increased levels of autoantibodies to P0 were treated with hormonotherapy and RT while in the remaining 25 patients with stable or slightly decreased levels of autoantibodies to $\mathrm{P} 0$ only $16 \%$ received the combined treatment $(\mathrm{p}=0.0814)$. In addition, 10 patients with increased levels of autoantibodies to P0 showed PSA mean level lower than the remaining 25 patients at 18 months ( 0.29 vs. $0.69, \mathrm{p}=0.0274)$ and at 24 months after therapy $(0.29$ vs. $0.81, \mathrm{p}=0.0813)$. Moreover, treatment of patients did not alter the level of antibodies against EGFR, ErbB2 and PSA. 


\section{Discussion}

Several studies have demonstrated the existence of antibodies to self-molecules in cancer patients, thus suggesting that the human immune system may recognize self-antigens $(35,42,43,45,53-57)$. Antigen tissue overexpression and exposure of sequestered antigens may explain tolerance circumvention (35). In this study we demonstrated that immunity to P0 protein $(\mathrm{p}=0.0279), \mathrm{ECM}$ molecules $(\mathrm{CI}$, $\mathrm{p}=0.0046$; CIII, $\mathrm{p}=0.0006 ; \mathrm{CV}, \mathrm{p}=0.0028 ; \mathrm{FN}, \mathrm{p}<0.0001$; and LM p=0.0004) and to HSP90 ( $\mathrm{p}=0.0406)$ was associated with malignancy in untreated prostate cancer patients. No patient serum showed antibodies to EGFR, while 2 and 1 patients showed reactivity to ErbB2 and PSA, respectively. In addition, we demonstrated that 8 months after therapy the $\mathrm{IgG}$ serum levels to CI $(p=0.0009)$, CIII $(p=0.0003), F N(p=0.0003)$ and HSP90 $(\mathrm{p}=0.0012)$ significantly decreased. Conversely, the level of autoantibodies to P0 increased after therapy in 10 patients $(\mathrm{p}=0.0020), 50 \%$ of the 10 patients with increased levels of autoantibodies to P0 were treated with hormonotherapy and radiotherapy (RT). Treatment of patients did not alter the level of antibodies against EGFR, ErbB2 and PSA.

The decrease of the levels of autoantibodies to ECM molecules and HSP90 after RT might not be surprising. It has been shown that ionizing radiation of mammary gland induced rapid-remodeling of the stromal ECM and modified the integrity of the epithelial basement membrane. Hence, it cannot be excluded that the increase or remodeling of ECM molecules at tumor levels could have increased the capture of anti-ECM antibodies in the irradiated area, thus determining their decreased concentration in the blood. Indeed, Collagen III was induced in the adipose stromal tissue of the mammary gland within 1 day after irradiation (24). Fibrosis, which represents excessive accumulation of collagen and other ECM components following unbalanced ECM synthesis and degradation, is a dose-limiting complication of RT at numerous primary anatomical sites (18). The increase of ECM at the site of irradiation could have promoted the uptake of anti-ECM antibodies in irradiated tissues, thereby determining their decline in the blood.

Prostasomes are secretory granules synthesized, stored and secreted by normal and neoplastic human prostate epithelial cells (58). It has been suggested that prostasomes in prostate cancer can be released into the blood circulation (58) and that the most frequently occurring prostasomal proteins are heat shock proteins (HSPs) (6). Radiation therapy has been demonstrated to increase the release of HSP72 in the blood of prostate cancer patients (59). Accordingly, autoantibodies to HSPs can bind circulating HSPs and form immunocomplexes which can be eliminated by phagocytosis (60). In addition, the elimination of prostate cancer cells after RT could have decreased immune system stimulation (61). Alternatively, the presence of immunocomplexes could have interfered with the detection of anti-HSP autoantibodies by ELISA. The decrease of IgG levels to HSP90 was associated with levels of Gleason prior to RT.

The strong in vivo immunogenicity of ribosomal $\mathrm{P} 0$ protein before or after therapy is not surprising. Different features of a given self-antigen concur to determine whether such antigen is apt to induce an autoreactive immune response (35). According to Plotz, these features encompass: a) the antigen structure; b) its immunological and pro-inflammatory properties; c) its expression level, and (d) its catabolism and fate after cell death (62). In view of that, ribosomal $\mathrm{P}$ proteins have long runs or clusters of charged residues and form large complexes. Indeed, serum of some patients with systemic lupus erythematosus (LES) contains autoantibodies to ribosomal $\mathrm{P}$ proteins $(40,41)$. Moreover, tissue inflammation induced by $\mathrm{RT}$ could have resulted in increased exposure of cryptic and/or modified ribosomal P0 epitopes and consequently in the stimulation of a specific immune response to the antigen.

The presence of anti-P0 autoantibodies following RT may have clinical implications. Monoclonal antibodies against human ribosomal $\mathrm{P}$ proteins were able to penetrate into cultured cells and cause apoptosis (44). In addition, the ribosomal P0 protein has been shown to be present in the cell membrane $(42,43)$. The increased expression of the C-22 epitope of $\mathrm{P} 0$ on the surface of pharynx cancer cells following cellular stress in vitro may indicate that anti-P0 autoantibodies could directly mediate apoptosis in this tumor (42). Indeed, 10 patients with increased levels of autoantibodies to P0 showed PSA mean level lower than the remaining 25 patients at 18 months $(0.29$ vs. $0.69, \mathrm{p}=0.0274)$ and at 24 months after therapy ( 0.29 vs. $0.81, \mathrm{p}=0.0813)$. Overall, our study shows for the first time that the therapy in patients with prostate cancer, while resulting in increased levels of serum antibodies to P0 protein, reduces their levels against ECM molecules or some HSPs. This phenomenon may be due to the different structure and properties of the antigens tested. Antibody to ribosomal P0 protein might have biological functions. In addition, the levels of autoantibodies to ECM components, HSPs and P0 protein might be an indicator of response to therapy in prostate cancer patients or could be used in patient monitoring and may contribute to the better understanding of the immunobiological behavior of tumor tissue following therapy.

\section{Acknowledgements}

This study was supported by Ministero dell'Istruzione, dell'Università e della Ricerca (MIUR, PRIN) (to A.M and R.B). LTR-EGFR and LTR-ErbB2 cells were provided by Dr Matthias Kraus. The authors thank Barbara Bulgarini for her editorial assistance in the preparation of the manuscript. We wish to thank nurse Franca Pietrasanta for assisting with the management of patients.

\section{References}

1. Jemal A, Bray F, Center MM, Ferlay J, Ward E and Forman D: Global cancer statistics. CA Cancer J Clin 61: 69-90, 2011.

2. D'Amico AV: Radiation and hormonal therapy for locally advanced and clinically localized prostate cancer. Urology 60 (Suppl 1): 32-37, 2002.

3. Palumbo C, Bei R, Procopio A and Modesti A: Molecular targets and targeted therapies for malignant mesothelioma. Curr Med Chem 15: 855-867, 2008.

4. McNeel DG, Nguyen LD, Storer BE, Vessella R, Lange PH and Disis ML: Antibody immunity to prostate cancer associated antigens can be detected in the serum of patients with prostate cancer. J Urol 164: 1825-1829, 2000.

5. Olson BM and McNeel DG: Antibody and T-cell responses specific for the androgen receptor in patients with prostate cancer. Prostate 67: 1729-1739, 2007. 
6. Ronquist KG, Carlsson L, Ronquist G, Nilsson S and Larsson A Prostasome-derived proteins capable of eliciting an immune response in prostate cancer patients. Int J Cancer 119: 847-853, 2006.

7. Massoner P, Lueking A, Goehler H, et al: Serum-autoantibodies for discovery of prostate cancer specific biomarkers. Prostate 72: 427-436, 2012

8. Agarwal N, Padmanabh S and Vogelzang NJ: Development of novel immune interventions for prostate cancer. Clin Genitourin Cancer 10: 84-92, 2012.

9. Mercader M, Bodner BK, Moser MT, et al: T cell infiltration of the prostate induced by androgen withdrawal in patients with prostate cancer. Proc Natl Acad Sci USA 98: 14565-14570, 2001.

10. Shimura S, Yang G, Ebara S, Wheeler TM, Frolov A and Thompson TC: Reduced infiltration of tumor-associated macrophages in human prostate cancer: association with cancer progression. Cancer Res 60: 5857-5861, 2000.

11. Vesalainen S, Lipponen P, Talja M and Syrjänen K: Histological grade, perineural infiltration, tumour-infiltrating lymphocytes and apoptosis as determinants of long-term prognosis in prostatic adenocarcinoma. Eur J Cancer 30A: 1797-1803, 1994.

12. Gulley JL and Drake CG: Immunotherapy for prostate cancer: recent advances, lessons learned, and areas for further research. Clin Cancer Res 17: 3884-3891, 2011

13. Nesslinger NJ, Ng A, Tsang KY, Ferrara T, Schlom J, Gulley JL and Nelson BH: A viral vaccine encoding prostate-specific antigen induces antigen spreading to a common set of self-proteins in prostate cancer patients. Clin Cancer Res 16: 4046-4056, 2010.

14. Becker JT, Olson BM, Johnson LE, Davies JG, Dunphy EJ and McNeel DG: DNA vaccine encoding prostatic acid phosphatase (PAP) elicits long-term T-cell responses in patients with recurrent prostate cancer. J Immunother 33: 639-647, 2010.

15. Kantoff PW, Schuetz TJ, Blumenstein BA, et al: Overall survival analysis of a phase II randomized controlled trial of a Poxviral-based PSA-targeted immunotherapy in metastatic castration-resistant prostate cancer. J Clin Oncol 28: 1099-1105, 2010.

16. Nesslinger NJ, Sahota RA, Stone B, et al: Standard treatments induce antigen-specific immune responses in prostate cancer Clin Cancer Res 13: 1493-1502, 2007.

17. Koukourakis MI: Radiation damage and radioprotectants: new concepts in the era of molecular medicine. Br J Radiol 85: 313-330, 2012

18. Yarnold $\mathbf{J}$ and Brotons MC: Pathogenetic mechanisms in radiation fibrosis. Radiother Oncol 97: 149-161, 2010.

19. Mothersill CE, Moriarty MJ and Seymour CB: Radiotherapy and the potential exploitation of bystander effects. Int J Radiat Oncol Biol Phys 58: 575-579, 2004.

20. Marzocchella L, Fantini M, Benvenuto M, Masuelli L, Tresoldi I, Modesti A and Bei R: Dietary flavonoids: molecular mechanisms of action as anti- inflammatory agents. Recent Pat Inflamm Allergy Drug Discov 5: 200-220, 2011.

21. Schmid TE and Multhoff G: Radiation-induced stress proteinsthe role of heat shock proteins (HSP) in anti-tumor responses. Curr Med Chem 19: 1765-1770, 2012

22. Boerma M, van der Wees CG, Vrieling H, et al: Microarray analysis of gene expression profiles of cardiac myocytes and fibroblasts after mechanical stress, ionising or ultraviolet radiation. BMC Genomics 6: 6, 2005 .

23. Niehoff P, Wiltfang J, Springer IN, Weppner N, Kimmig B and Acil Y: Increased excretion of collagen crosslinks in irradiated patients indicates destruction of collagen. Int J Radiat Biol 82: 503-509, 2006

24. Ehrhart EJ, Gillette EL and Barcellos-Hoff MH: Immunohistochemical evidence of rapid extracellular matrix remodeling after iron-particle irradiation of mouse mammary gland. Radiat Res 145: 157-162, 1996.

25. Harriss W, Bezak E, Yeoh E and Hermans M: Measurement of reoxygenation during fractionated radiotherapy in head and neck squamous cell carcinoma xenografts. Australas Phys Eng Sci Med 33: 251-263, 2010

26. Magagnin MG, Sergeant K, van den Beucken T, et al: Proteomic analysis of gene expression following hypoxia and reoxygenation reveals proteins involved in the recovery from endoplasmic reticulum and oxidative stress. Radiother Oncol 83: 340-345, 2007.

27. Izzi V, Masuelli L, Tresoldi I, Foti C, Modesti A and Bei R: Immunity and malignant mesothelioma: from mesothelial cell damage to tumor development and immune response-based therapies. Cancer Lett 322: 18-34, 2012.
28. Fernandez-Madrid F, Karvonen RL, Kraut MJ, Czelusniak B and Ager JW: Autoimmunity to collagen in human lung cancer. Cancer Res 56: 121-126, 1996.

29. Kalluri R, Petrides S, Wilson CB, et al: Anti-alpha1(IV) collagen autoantibodies associated with lung adenocarcinoma presenting as the Goodpasture syndrome. Ann Intern Med 124: 651-653, 1996.

30. Tong YQ, Zhang ZJ, Liu B, et al: Autoantibodies as potential biomarkers for nasopharyngeal carcinoma. Proteomics 8: 3185-3193, 2008

31. Young AL, Bailey EE, Colaço SM, Engler DE and Grossman ME: Anti-laminin-332 mucous membrane pemphigoid associated with recurrent metastatic prostate carcinoma: hypothesis for a paraneoplastic phenomenon. Eur J Dermatol 21: 401-404, 2011.

32. Bei R, Masuelli L, Palumbo C, Tresoldi I, Scardino A and Modesti A: Long-lasting tissue inflammatory processes trigger autoimmune responses to extracellular matrix molecules. Int Rev Immunol 27: 137-175, 2008

33. Bei R, Mentuccia D, Trono P, et al: Immunity to extracellular matrix antigens is associated with ultrastructural alterations of the stroma and stratified epithelium basement membrane in the skin of Hashimotos thyroiditis patients. Int J Immunopathol Pharmacol 19: 661-674, 2006.

34. Masuelli L,Pompa G,Fabrizi M, et al: Patients with periimplantitis, unlike those with a healthy peri-implant microenvironment, display antibodies to more than one heat shock protein (HSP 27, HSP 65 and HSP 90) linear epitope. Eur J Inflammation 9: 257-268, 2011.

35. Bei R, Masuelli L, Palumbo C, Modesti M and Modesti A: A common repertoire of autoantibodies is shared by cancer and autoimmune disease patients: inflammation in their induction and impact on tumor growth. Cancer Lett 281: 8-23, 2009.

36. Jego G, Hazoumé A, Seigneuric R and Garrido C: Targeting heat shock proteins in cancer. Cancer Lett: Nov 13, 2010 (Epub ahead of print).

37. Suzuki H, Sugimura $\mathrm{H}$ and Hashimoto K: Overexpression of heat shock protein 27 is associated with good prognosis in the patient with oral squamous cell carcinoma. Br J Oral Maxillofac Surg 45: 123-129, 2007.

38. Wahl MC and Moller W: Structure and function of the acidic ribosomal stalk proteins. Curr Protein Pept Sci 3: 93-106, 2002.

39. Koscec M, Koren E, Wolfson-Reichlin M, et al: Autoantibodies to ribosomal $\mathrm{P}$ proteins penetrate into live hepatocytes and cause cellular dysfunction in culture. J Immunol 159: 2033-2041, 1997.

40. Mahler M, Kessenbrock K, Szmyrka M, et al: International multicenter evaluation of autoantibodies to ribosomal $\mathrm{P}$ proteins Clin Vaccine Immunol 13: 77-83, 2006.

41. Gerli R and Caponi L: Anti-ribosomal P protein antibodies. Autoimmunity 38: 85-92, 2005

42. Bei R, Masuelli L, Trono P, et al: The ribosomal P0 protein induces a spontaneous immune response in patients with head and neck advanced stage carcinoma that is not dependent on its overexpression in carcinomas. Int J Oncol 31: 1301-1308, 2007.

43. Marzocchella L, Sini V, Buonomo O, et al: Spontaneous immunogenicity of ribosomal P0 protein in patients with benign and malignant breast lesions and delay of mammary tumor growth in P0-vaccinated mice. Cancer Sci 102: 509-515, 2011.

44. Sun KH, Tang SJ, Lin ML, Wang YS, Sun GH and Liu WT: Monoclonal antibodies against human ribosomal $\mathrm{P}$ proteins penetrate into living cells and cause apoptosis of Jurkat T cells in culture. Rheumatology 40: 750-756, 2001.

45. Bei R, Masuelli L, Moriconi E, Visco V, Moretti A, Kraus MH and Muraro R: Immune responses to all ErbB family receptors detectable in serum of cancer patients. Oncogene 18: 1267-1275, 1999.

46. Masuelli L, Focaccetti C, Cereda V, et al: Gene-specific inhibition of breast carcinoma in BALB-neuT mice by active immunization with rat Neu or human ErbB receptors. Int J Oncol 30: 381-392, 2007.

47. Bei R, Pompa G, Vitolo D, et al: Co-localization of multiple ErbB receptors in stratified epithelium of oral squamous cell carcinoma. J Pathol 195: 343-348, 2001.

48. Masuelli L, Marzocchella L, Focaccetti C, et al: Local delivery of recombinant vaccinia virus encoding for neu counteracts growth of mammary tumors more efficiently than systemic delivery in neu transgenic mice. Cancer Immunol Immunother 59: $1247-1258,2010$.

49. Masuelli L, Marzocchella L, Quaranta A, et al: Apigenin induces apoptosis and impairs head and neck carcinomas EGFR/ErbB2 signaling. Front Biosci 16: 1060-1068, 2011. 
50. Masuelli L, Bei R, Sacchetti P, et al: Beta-catenin accumulates in intercalated disks of hypertrophic cardiomyopathic hearts. Cardiovasc Res 60: 376-387, 2003.

51. Masuelli L, Marzocchella L, Focaccetti C, et al: Resveratrol and diallyl disulfide enhance curcumin-induced sarcoma cell apoptosis. Front Biosci 17: 498-508, 2012.

52. Masuelli L, Budillon A, Marzocchella L, et al: Caveolin-1 overexpression is associated with simultaneous abnormal expression of the E-cadherin $/ \alpha-\beta$ catenins complex and multiple ErbB receptors and with lymph nodes metastasis in head and neck squamous cell carcinomas. J Cell Physiol 227: 3344-3353, 2012.

53. Bei R, Budillon A, Reale MG, et al: Cryptic epitopes on alpha-fetoprotein induce spontaneous immune responses in hepatocellular carcinoma, liver cirrhosis, and chronic hepatitis patients. Cancer Res 59: 5471-5474, 1999.

54. Turriziani M, Fantini M, Benvenuto M, et al: Carcinoembryonic antigen (CEA)-based cancer vaccines: recent patents and antitumor effects from experimental models to clinical trials. Recent Pat Anticancer Drug Discov 7: 265-296, 2012.

55. Bei R and Mizejewski GJ: Alpha fetoprotein is more than a hepatocellular cancer biomarker: from spontaneous immune response in cancer patients to the development of an AFP-based cancer vaccine. Curr Mol Med 11: 564-581, 2011.
56. Bei R, Budillon A, Masuelli L, et al: Frequent overexpression of multiple ErbB receptors by head and neck squamous cell carcinoma contrasts with rare antibody immunity in patients. J Pathol 204: 317-325, 2004.

57. Scardino A, Alimandi M, Correale P, et al: A polyepitope DNA vaccine targeted to Her-2/ErbB-2 elicits a broad range of human and murine CTL effectors to protect against tumor challenge. Cancer Res 67: 7028-7036, 2007.

58. Larsson A, Ronquist G, Wülfing C, et al: Antiprostasome antibodies: possible serum markers for prostate cancer metastasizing liability. Urol Oncol 24: 195-200, 2006.

59. Hurwitz MD, Kaur P, Nagaraja GM, Bausero MA, Manola J and Asea A: Radiation therapy induces circulating serum Hsp72 in patients with prostate cancer. Radiother Oncol 95: 350-358, 2010.

60. Knobloch V and Plundrová D: Immunocomplexes in pregnancy. II. Phagocytosed complexes in the peripheral blood. Cesk Gynekol 51: 611-616, 1986 (In Czech).

61. Kossenkov AV, Vachani A, Chang C, et al: Resection of non-small cell lung cancers reverses tumor-induced gene expression changes in the peripheral immune system. Clin Cancer Res 17: 5867-5877, 2011.

62. Plotz PH: The autoantibody repertoire: searching for order. Nat Rev Immunol 3: 73-78, 2003. 